\title{
The Effect of the Number of Open Vertebral Segments on the Prognosis of Newborns with Midline Closure Defect: A Single Surgeon, Single Center Experience
}

\author{
Ahmet CETINKAL, Alican TAHTA \\ Istanbul Medipol University, Faculty of Medicine, Department of Neurosurgery, Istanbul, Turkey \\ Corresponding author: Ahmet CETINKAL ahmet.cetinkal@medipol.com.tr
}

\section{ABSTRACT}

AIM: To investigate the effect of the number of open vertebral segments on the prognosis of newborns with midline closure defects (MCD), and the optimal timing for ventriculoperitoneal shunt (VPS) placement in those with MCD accompanied by hydrocephalus.

MATERIAL and METHODS: A total of 63 patients (35 girls and 28 boys) were admitted to the neonatal intensive care unit between April 2016 and January 2019. The patients' MCDs were examined in terms of type, localization, number of open vertebral segments, accompanying hydrocephalus (HC), surgical technique, and complications.

RESULTS: The mean follow-up period was 12 months (6-24 months). Ten cases of meningocele (M) (15.9\%), 41 cases of myelomeningocele (MM) (65\%), and 12 cases of encephalocele (E) (19.1\%) were identified. A VPS was inserted in 44 (69.8\%) patients (E, 8; MM, 34; and M, 2), performed in 33 patients during the same admission, while 11 were shunted after discharge during the follow-up period. Thirty-four of the 41 cases of $\mathrm{MM}$ and all cases of $\mathrm{M}$ and $\mathrm{E}$ were primarily closed, while the remaining MMs required skin flaps. The $\mathrm{M}$ and $\mathrm{MM}$ cases were categorized according to the number of open vertebral segments and examined in terms of neurological deficit, length of hospital stay, and complications.

CONCLUSION: In all pediatric cases, case-by-case evaluation, attention to hypothermia and meticulous hemostasis, protection of functional neural tissue, closing the defect as soon as possible, and treating accompanying HC during the same session, were considered. Additionally, the neural tissue density correlated with the number of open vertebral segments and it was considered prognostically more valuable.

KEYWORDS: Newborn, Midline closure defect, Hydrocephalus, Surgical treatment

ABBREVIATIONS: MCD: Midline Closure Defect, M: Meningocele, MM: Myelomeningocele, E: Encephalocele, VPS: Ventriculoperitoneal shunt, HC: Hydrocephalus, ETV: Endoscopic third ventriculostomy

\section{INTRODUCTION}

$\mathrm{M}$ idline closure defects (MCDs) are congenital malformations that still exist despite modern medical technologies. They cause heavy social and economic problems to the society $(9,37)$. MCDs appear in the first weeks of embryogenesis due to the closure defects occurring in the brain, spinal cord, and spine $(1,25,37)$. An encephalocele $(E)$ is formed as a result of the neural tube not closing in the early period, and a failure of closure in the later period of embryogenesis leads to a meningocele (M) or a myelomeningocele (MM) (4). In E, neural tissues usually herniate into the sac due to occipital bone defects (40). MM is the most common form of MCD, with an incidence of $1 / 1000$, and is seen in 4.4-4.6 of 10.000 live births in the USA (38). M is a cystic lesion, and involves the cerebrospinal fluid (CSF) and the dura covered by a membrane, with no neural tissue in the 
sac $(9,14)$. E is a subtype of MM located in the cranium $(11,40)$. The prognosis of these malformations, which are often seen as sac structures, varies according to the size and location of the sac, and accompanying anomalies $(1,36)$. The choice of treatment is surgery. Skin closure, repair of dural defects, and preservation of neurological function are the main goals of surgery, aiming to close the skin defect with restoration of the neural plate and the dura, respectively, after careful preoperative planning for maximum protection of neural functions with care taken for hemostasis and hypothermia. In our study, we aimed to discuss the effect of the number of open vertebral segments on prognosis, and also the ideal timing of ventriculoperitoneal shunt (VPS) placement for accompanying hydrocephalus $(\mathrm{HC})$ in newborns with MCD, in light of the current literature.

\section{MATERIAL and METHODS}

This study was conducted in accordance with Istanbul Medipol University Ethics Committee (E-10840098-772.02-2658).

Sixty-three neonatal patients with a gestational age of over 36 weeks, birth weight of more than $2500 \mathrm{~g}$, and no apparent accompanying disease were included in the study. All surgeries were performed by the same surgeon at the same center. The cases were evaluated retrospectively, and the MCDs were examined in terms of type, localization, concomitant anomaly, surgical technique, and complications. Newborns with $M$ (Figure 1A-E), MM (Figure 2A-F), and E (Figure 3A-F) were included in the study and followed up for at least 6 months (range, 6-24 months). Patients with severe anomalies related to other organ systems were excluded.

The patients' spinal magnetic resonance imaging (MRI) scans were evaluated and they were divided into two groups according to the number of open vertebral segments. Group
1 included patients with one or two open vertebral segment anomalies (Figure 4A-G), and Group 2 included those with three or more open vertebral segment anomalies (Figure 5AI). When all the spinal MRls of the newborns were examined, some of the sacs were very large, despite being accompanied by small defects, making surgical treatment more reasonable. Therefore, as previously stated, newborns were grouped according to the number of open posterior vertebral segments.

Physical and neurological examinations, including height, weight, and head circumference of the newborns, were evaluated. Blood urea and creatinine levels, and urogenital ultrasonography (USG) were performed to detect urological abnormalities. Complete blood count, routine erythrocyte sedimentation rate (ESR), and C-reactive protein (CRP) values were evaluated for infection. The MRls were examined to evaluate the sac content and the presence of additional spinal anomalies in all patients. Patients with low birth weight and germinal matrix bleeding were excluded from the study. All surgeries were performed under general anesthesia with an intravenous antibiotic injection 30 minutes before surgery. The antibiotic was continued for 72 hours after the surgery. Spinal and cranial MRI or computed tomography (CT) scans were evaluated, and the sac size, number of defective segments, accompanying $\mathrm{HC}$, and additional anomalies were analyzed. In addition, in newborns with accompanying $\mathrm{HC}$ with an Evan's rate of over $50 \%$, two medium-pressure VPSs (Novus ${ }^{T M}$, Integra ${ }^{\circledR}, N J$, USA) were placed during the same session after repairing MCD. Duration of hospitalization, antibiotic treatment, and morbidity were evaluated according to patient characteristics. Prognosis and complications were recorded during the follow-up.

\section{Statistical Analyses}

Raw data were analyzed using a demographic statistical

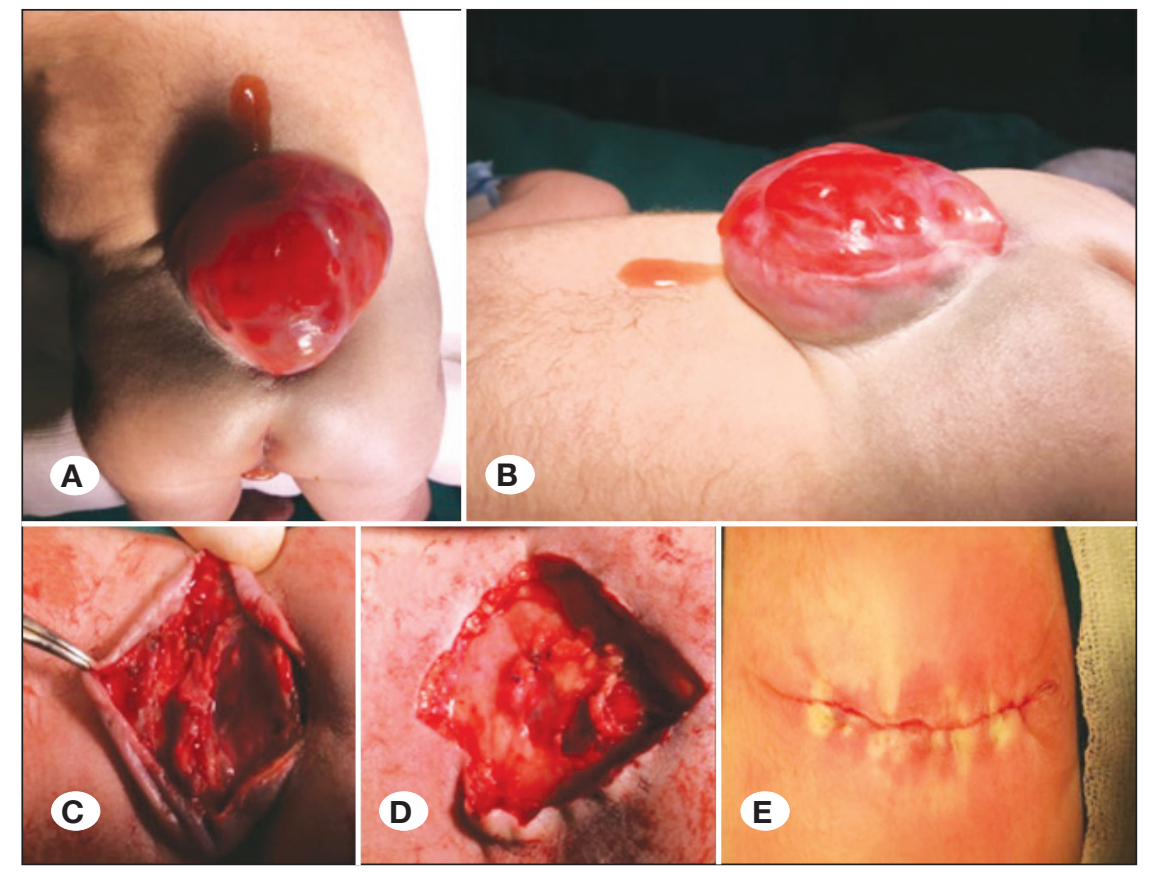

Figure 1A-E: Lumbar meningocele.

Preoperative (A, B), intraoperative (C, D), and postoperative images. 
method. Mann-Whitney U, chi-square, and Fisher's exact tests were used. The confidence interval was 0.95, and statistical significance was set at $p<0.05$. PSPP (a free software application for analysis of sampled data, intended as a free alternative for IBM SPSS Statistics) and Microsoft Excel were used.

\section{RESULTS}

Demographics, anatomical localization of the sac, accompanying $\mathrm{HC}$, and VPS complications in newborns are presented in Table I. Our patients were predominantly newborns with $\mathrm{MM}(65 \%, \mathrm{n}=41) . \mathrm{M}$ and $\mathrm{MM}$ were
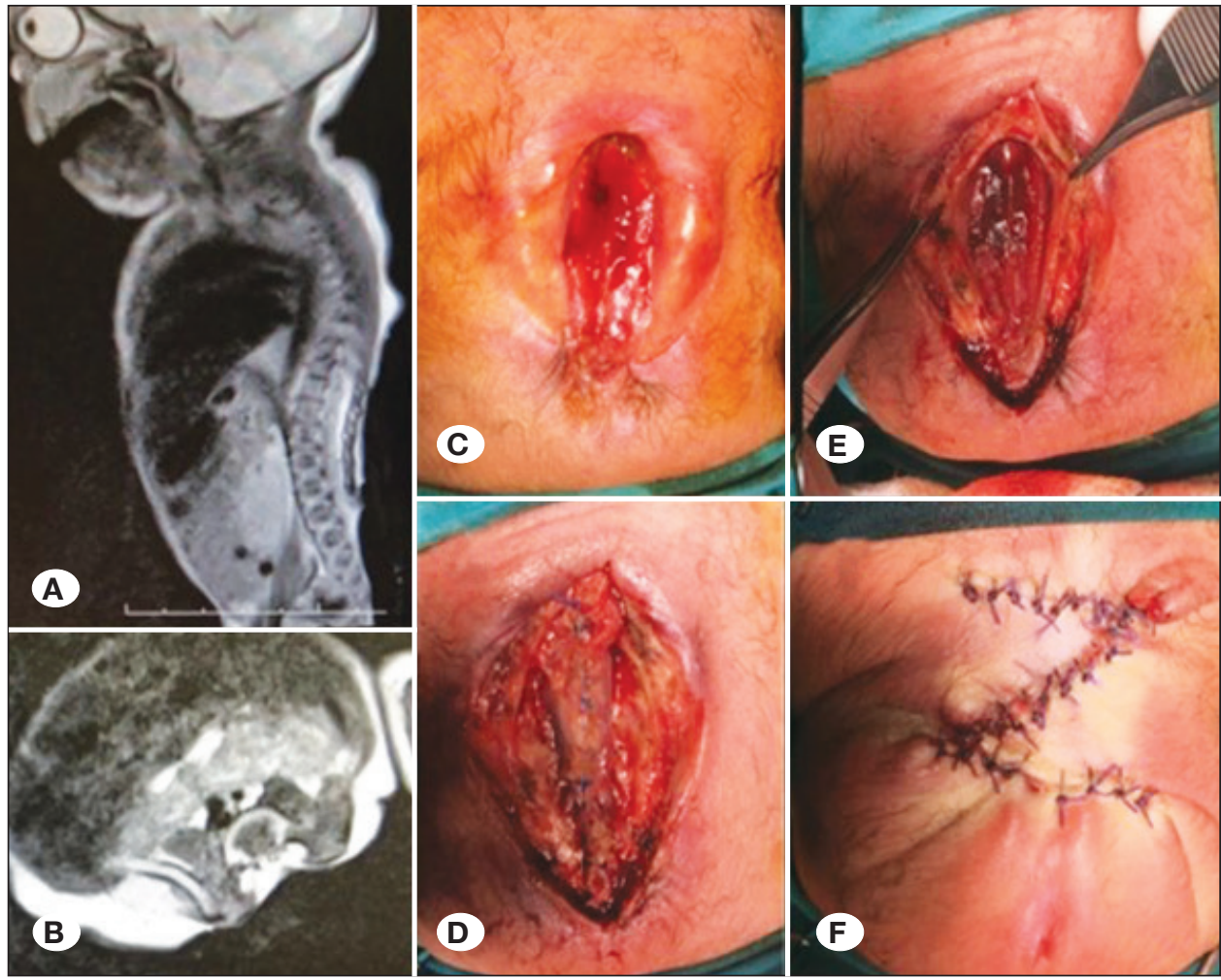

Figure 2: Lumbar

myelomeningocele. T2-weighted sagittal (A), and axial (B) magnetic resaonance imaging studies.

Preoperative (C), intraoperative (D, E), and postoperative (F) images.
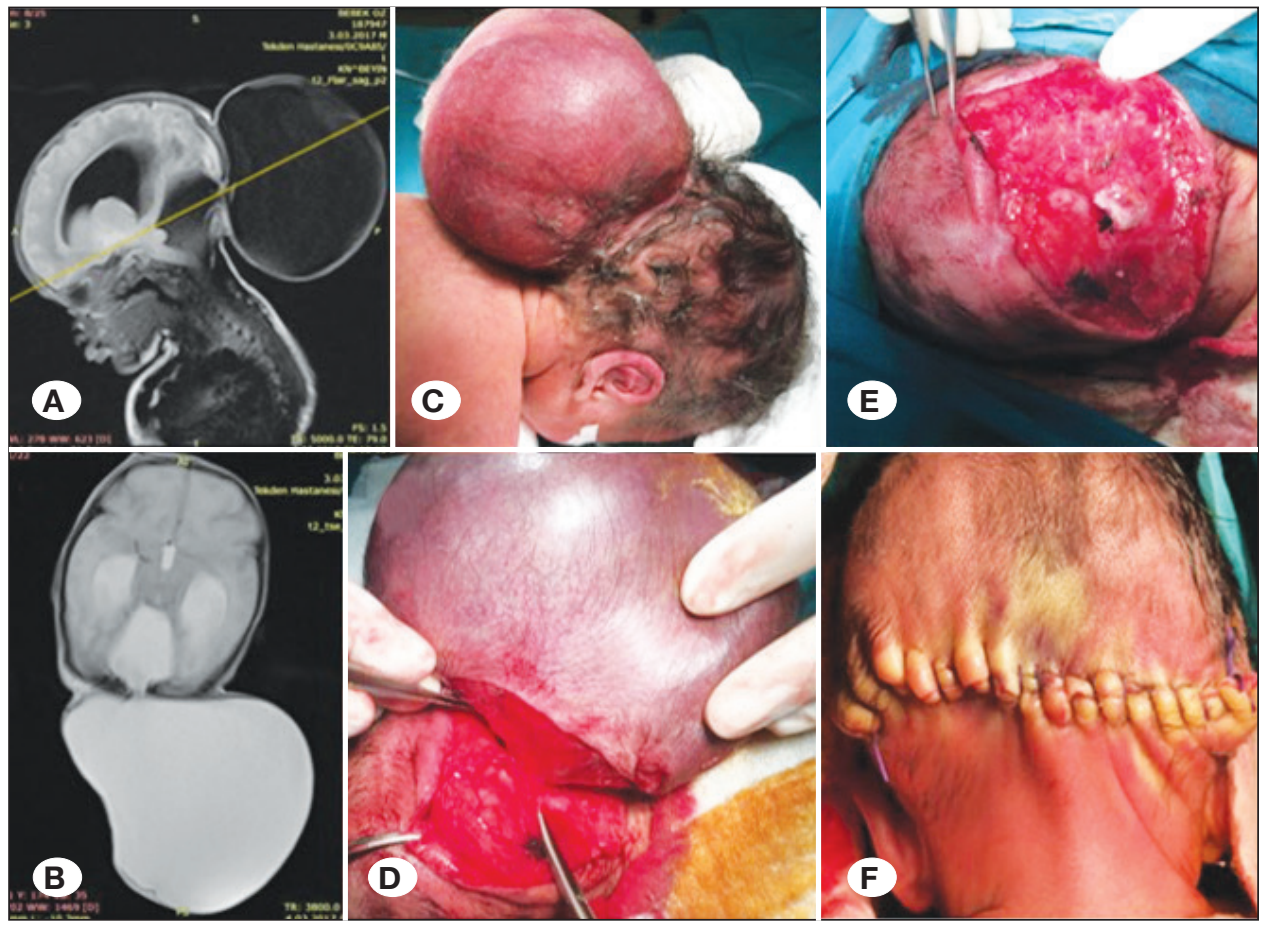

Figure 3: Occipital encephalocele. T1-weighted sagittal (A), and T2-weighted axial (B) magnetic resonance imaging studies. Preoperative (C), intraoperative (D, E), and postoperative (F) images. 


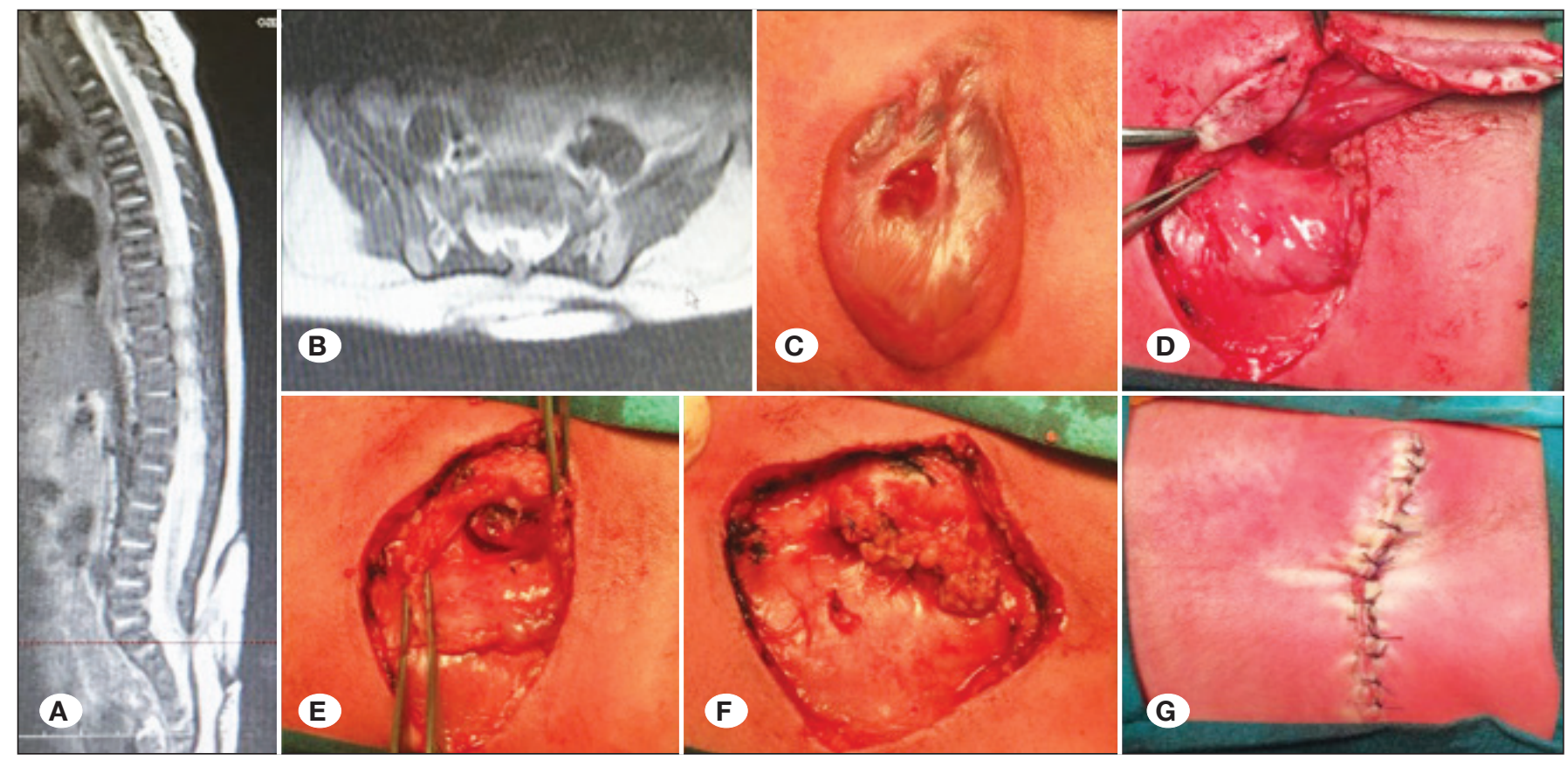

Figure 4: Group 1. T2-weighted sagittal (A), and axial (B) magnetic resonance imaging studies. Preoperative (C), intraoperative (D, E, F), and postoperative (G) images.


Figure 5: Group 2. T2-weighted (A), and T1-weighted (B) lumbar, sagittal magnetic resonance (MR) imaging studies. T2-weighted sagittal (C) (red arrow shows tonsillar herniation), and axial (D) MR images. E) Postoperative image after ventriculoperitoneal shunt surgery. Preoperative (F), intraoperative (G) and postoperative images (H, I). 
predominantly localized in the lumbar region $(64.7 \%, n=33)$. $\mathrm{HC}$ was detected in $82.9 \%(n=34)$ of MM cases; this rate was $65.9 \%(n=27)$ at birth. Likewise, VPS was placed in $66.6 \%(n=8)$ of $E$ cases; this rate was $41.6 \%(n=5)$ at birth. Additionally, VPS surgery was performed in 2 (20\%) of the $10 \mathrm{M}$ cases; this rate was $10 \%(n=1)$ at birth. In total, we performed VPS surgery in 44 patients (69.8\%), and shunt complications occurred mostly in patients with MM $(29.3 \%, n=12)$. The most common complications were wound dehiscence $(36 \%, n=16)$ and proximal end obstruction of the VPS (15.9\%, $n=7)$.
With respect to open vertebral segments, the number of cases, neurological conditions of newborns, duration of hospitalization, and complications are shown in Table II. There were 30 patients (58.8\%) in Group 1 and 21 patients (41.2\%) in Group 2. When the neurological signs of the newborns were examined, the neurological deficit rate in Group 1 was 53.3\% $(n=16)$ and $76.2 \%(n=16)$ in Group 2. Wound dehiscence and CSF leakage were found to be increased in Group 2, which naturally increased the length of hospital stay and antibiotic administration period, and significantly reduced complication rates in Group $1(\mathrm{p}=0.0001, \mathrm{p}=0.001$, and $\mathrm{p}=0.012$, respectively).

Table I: Characteristics of Cases

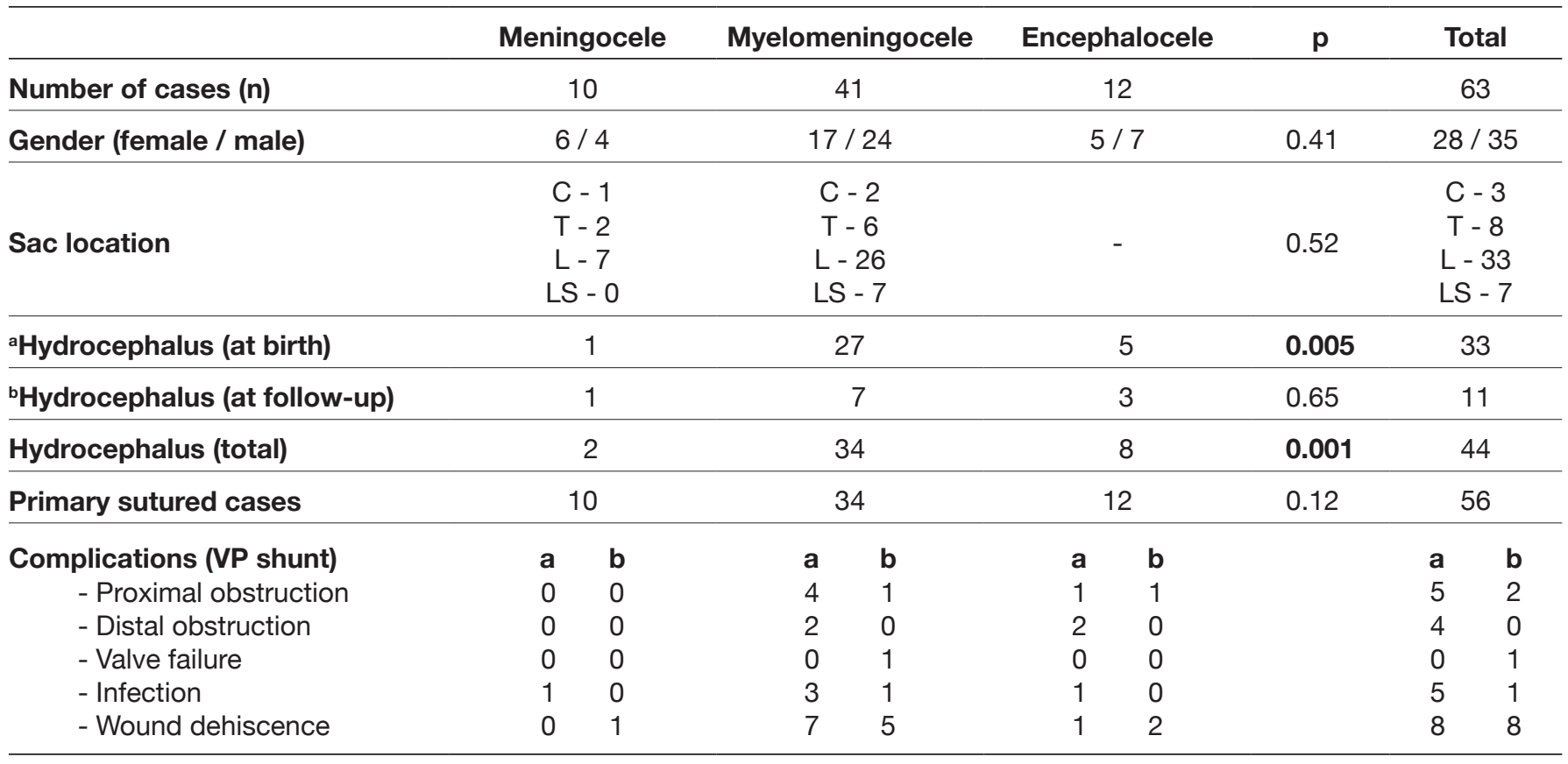

C: Cervical, T: Thoracal, L: Lumbal, LS: Lumbosacral, a: Hydrocephalus at birth, b: Hydrocephalus at follow-up.

Table II: Characteristics of Cases according to Open Anomaly Vertebral Segment Prevalence

\begin{tabular}{lccc}
\hline & Group 1 & Group 2 & p \\
\hline Number of cases $(\mathbf{n})$ & 30 & 21 & 0.21 \\
\hline Neurological condition & & & \\
\hline - Paraplegia & 6 & 10 & $\mathbf{0 . 0 3 6}$ \\
\hline - Paraparesis & 7 & 5 & 0.97 \\
\hline - Monoparesis & 3 & 1 & 0.49 \\
\hline Hospitalization (days) & $7 \pm 3$ & $15 \pm 4$ & $\mathbf{0 . 0 0 0 1}$ \\
\hline Antibiotic administration (days) & $4 \pm 2$ & $7 \pm 3$ & $\mathbf{0 . 0 0 1}$ \\
\hline Complications & 8 & 13 & $\mathbf{0 . 0 1 2}$ \\
\hline$\quad$ - CSF leak & 0 & 2 & 0.16 \\
\hline - Wound infection & 1 & 6 & $\mathbf{0 . 0 1 5}$ \\
\hline - Wound dehiscence & 7 & 5 & 0.97 \\
\hline
\end{tabular}




\section{DISCUSSION}

Closure of MCD and associated HC management are two of the most basic, but never simple, features of pediatric neurosurgery. MMs have been reported to be five times more common than $\mathrm{M}$, and are more common in girls than in boys $(18,19,24)$. In our study, the incidence of MM was four times higher than that of $\mathrm{M}$, and $\mathrm{MM}$ was more common in girls (male: $44.4 \%, \mathrm{n}=28$; female: $55.5 \%, \mathrm{n}=35$ ). In our MM cases, the F/M ratio was 1.4/1, while it was 1.2/1 in Musluman et al.'s series (36).

It has been reported that the lumbar region is the most common location for $\mathrm{MM}(1,14,25)$. Faraj et al. reported that $60 \%$ of MMs were located in the lumbar region (15). In our study as well, the lumbar region was the most common location for $\mathrm{MM}(63.4 \%, \mathrm{n}=26)$.

Neurological, orthopedic, and urological anomalies may be associated with $\mathrm{MM}$. The most common one is $\mathrm{HC}$, occurring at a rate of $80 \%-90 \%$ (41). Therefore, in this section, we particularly focus on the associated HC (excluding other related symptoms, such as urologic and orthopedic anomalies). Eseoglu et al. reported that $\mathrm{HC}$ often coexists in patients with $\mathrm{MM}$, and they detected $\mathrm{HC}$ in $73.4 \%$ of their cases (14). Müslüman et al. reported that $62.3 \%$ of cases with MM were accompanied by HC (36). Among our cases, $82.9 \%$ $(\mathrm{n}=34)$ of MM were accompanied by HC. In MM, HC can occur at the time of birth or later during growth and development because of craniocervical junction anomalies and/or Sylvian aqueduct stenosis (5). Although $27(65 \%)$ of our 41 patients with MM had VPS placement at birth, $\mathrm{HC}$ was detected in seven patients in the $1^{\text {st }}$ month of follow-up.

Surgery is the treatment of choice for the management of MM. Intrauterine surgery aims to minimize the prolonged time of contact between the amniotic fluid and the sac, reducing the risk of brainstem herniation and nerve root irritation, thereby decreasing the risk of development of postpartum $\mathrm{HC}(16,35)$. Early randomized controlled studies have suggested that MM patients benefit from prenatal surgical treatment $(6,16)$. Moron et al. reported a $70 \%$ success rate in Chiari malformations using open fetal surgery, with extremely low surgical failure and perinatal mortality rates, and no maternal mortality or serious maternal morbidity (35). There are also studies reporting the risk of preterm labor, abortion, and premature rupture of membranes in intrauterine fetal surgery $(29,35)$.

Although there are many opinions on the timing of postpartum surgical treatment in the literature, the most common has been to perform surgery in the first 72 hours, under suitable conditions $(14,15,21,25,36,43)$. Early (in the first 72 hours) radical surgical approach (sac repair and VPS placement in the same session in appropriate cases) in newborns with MM reduces morbidity and mortality rates, causes lower infection rates, and reduces the length of stay $(14,25,41)$. Ulsenheimer et al. reported that correction of MM should be performed as soon as possible, preferably in the first 72 hours, and they stated that the 14 patients who had developed infection in their 31 patient-series had developed it due to delayed timing of surgery, and that they reduced the morbidity rate with appropriate antibiotic therapy (43). Jabaiti et al. divided their patients into two groups as early- and late-operated, in an MM series of 48 cases (23). They reported infection rates of $19.5 \%$ (in 2 of 19 patients) in the early repair group and $20.7 \%$ (6 of 29 patients) in the late repair group (23).

Another challenging topic is the management of $\mathrm{HC}$ in newborns, particularly when it is complicated with MCD and/ or other accompanying anomalies. In a recent meta-analysis study of medical records between and 1998-2014, McCarthy et al. stated that shunt malfunction and infection rates did not differ between delayed and simultaneous $\mathrm{HC}$ treatment, although recently, $\mathrm{HC}$ treatment has become more delayed. Additionally, they proposed that inpatient $\mathrm{HC}$ treatment failure rate was twice as high in patients who received endoscopic third ventriculostomy (ETV) treatment. This supports the argument that the effectiveness of ETV in children under 1 year of age is still controversial (30). Recently, in a case series consisting of 45 newborns (35.7\%) and 81 infants (64.3\%), Salem-Memou et al. reported that VPS was the first-line treatment in newborns (68.8\%), while ETV was the preferred approach in infants (74.1\%), with an overall complication rate of $26.1 \%(57.6 \%$ for VPS and $4.1 \%$ for ETV) (39). Moreover, in a systematic review, Blount et al. ascertained that there was insufficient data to conclude that ventricular size and morphology affect neurocognitive development (7). We operated on our cases as soon as possible in the first 72 hours (range, 1-9 days). In the presence of accompanying $\mathrm{HC}$, we placed VPS in the same session. Despite performing the surgery as soon as possible and using appropriate prophylactic antibiotics, the infection rate was $13.6 \%(n=6)$. In some studies, the mortality rate of patients with $\mathrm{MM}$ was reported to be approximately $14 \%$ $(27,31)$. Gross et al. reported no mortality in their series (19). This rate was $32 \%$ in a series by Mirzai et al. (33). No mortality was observed in the present study.

We believe that although a prognostic correlation with the diameter of the sac and the neural content present in the sac has been reported, the neck of the sac is also an important prognostic factor, depending on the number of vertebrae involved, just like the importance of the neck of an aneurysm while planning the treatment of a cerebral aneurysm. In the literature, we did not encounter any study examining the effect of the number of open vertebral segments on the prognosis of $\mathrm{M}$ and MM. However, there are some studies concerning the effect of sac diameter and sac localization on prognosis $(14,36)$. In their series of 64 cases, Eseoglu et al. reported that sac localization had no effect on prognosis. However, the diameter of the sac and the presence of neural tissue within the sac are important prognostic factors (14). Müslüman et al. reported that babies with a sac smaller than $25 \mathrm{~cm}^{2}$ could be operated on without the need for a flap, resulting in a lower risk of infection, shorter hospitalization period, and better prognosis (36). Additionally, with respect to fetoscopic sac repair, Corroenne et al. concluded that prenatal repair of patients with large NTD (over $170 \mathrm{~mm}^{2}$ at referral for the evaluation of a prenatal NTD repair) presented a lower proportion of hindbrain herniation reversal 6 weeks after surgery, a higher risk of dehiscence, and a higher need for postnatal repair (12). In our study, patients with smaller 
sacs were classified as Group 1, which had a significantly better prognosis than Group 2, similar to other studies in the literature. We also found that as the number of involved vertebrae increased, the neural tissue content that migrated into the sac also increased. All of our $\mathrm{M}$ cases were classified as Group 1. Our MM cases were more commonly found in Group 2; therefore, pathological findings on neurological examination were more frequent in Group 2 than in Group 1 (paraplegia, $p=0.036$ ). We found that the number of open vertebrae was strongly correlated with prognosis and that the duration of hospitalization was significantly lower in Group 1 than in Group $2(p<0.0001)$.

Encephalocele is a MCD that develops due to closure defects of the calvarial bones at various stages and locations, frequently in the occipital bone $(27,32)$. The meningocele sac contains only CSF, and the additional presence of cerebral or cerebellar tissue present makes it an encephalocele (32). It can be found with $\mathrm{HC}$ as well $(11,27,32)$. In a series of encephalocele patients, Shokunbi, Chapman, Lorber, and Mealey reported associated $\mathrm{HC}$ rates of $16 \%, 50 \%, 65 \%$, and $36 \%$, respectively $(11,27,32,40)$. HC was present in $66 \%$ of our encephalocele cases.

Split cord malformations may accompany MMs; however, they are often underdiagnosed, and patients may be discharged without appropriate treatment $(18,38)$. Iskandar et al. reported that in their MM series, $6 \%$ of patients had accompanying split cord malformation (22). None of the patients in our study had split cord malformations. However, we detected type II Chiari malformation in 17 cases (26.9\%) and type II Chiari malformation accompanied by holocord syringohydromyelia in one patient with MM.

Neurological deterioration, wound infection, CSF leakage, shunt infection, and acquired Chiari malformations are the main complications of MM surgery (1). Anegbe et al. reported that infection of the neural placode, $\mathrm{HC}$, location of the lesions above the lumbar region, and surgical repair were statistically significant risk factors for intracranial infection among myelomeningocele patients (3). The incidence of shunt complications has been found to be $22.6 \%-66 \%$ in the first year after surgery for MCD and VPS $(2,10,13,17,20,26)$. ETV was proposed for avoiding shunt-related complications. Although ETV was associated with a statistically significantly lower risk of procedure-related infection compared to shunts, the mortality, CSF leak, and reoperation rates were similar between ETV and shunt groups for pediatric $\mathrm{HC}$ in a systematic literature review including a search of PubMed (Medline) and Cochrane until October 2018 (42). Furthermore, Zhao et al. proposed ETV for patients younger than 3 years with obstructive or communicating $\mathrm{HC}$ in the event of shunt malfunction with a $40.5 \%$ (15/37) overall ETV failure rate (44). Alatas et al. evaluated 52 patients with myelomeningocele. Thirty-one patients required placement of VPS, and seven patients (22.6\%) underwent shunt revision within the first year of life (2). Caldarelli et al. found at least one shunt malfunction in $45.9 \%$ of patients $(78 / 170)$ during the 1 -year postoperative observation period (8). Regarding the aspect of reducing shunt infection rate, Mohamed Moussa et al. stated that injection of prophylactic vancomycin and gentamicin in and around the shunt hardware significantly reduced the incidence of postoperative shunt infection in congenital $\mathrm{HC}$ patients who underwent VP shunt insertion (34). In our series, we detected shunt-related complications in 20 patients (45.5\%), excluding a case of wound dehiscence that was repaired under local anesthesia. Although this rate is similar to those reported in the literature, it was found to be slightly higher. This could be due to simultaneous MCD repair and VPS placement in $75 \%$ of our patients in our study. According to the literature, the timing of VPS placement in patients with midline closure defects is controversial $(4,28)$. However, this will be the subject of another planned study.

\section{CONCLUSION}

The duration of operation, length of stay, and morbidity rates in Group $1 \mathrm{MCD}$ patients were lower than those of Group 2 MCD patients, according to the number of MCD-affected vertebrae. The neurological findings in Group 1 were closer to normal. In Group 2 (patients with an anomaly involving three or more levels of vertebrae), complications such as infection and CSF leakage were found to be increased, causing increased length of stay and morbidity rates. In M and MM, the density of the neural tissue in the sac and the number of affected vertebrae were negative prognostic factors. In pediatric cases, the major points of concern are avoiding hypothermia and maintaining hemostasis while preserving neural tissue, closing the defect as soon as possible, and placing VPS if there is accompanying hydrocephalus during the same session. This study represents a limited sample of newborns with MCD. Multicenter prospective studies, including a larger patient series, are required.

\section{REFERENCES}

1. Akalan $\mathrm{N}$ : Myelomeningocele (open spina bifida)-surgical management. Adv Tech Stand Neurosurg (37):113-141, 2011

2. Alatas I, Canaz G, Kayran NA, Kara N, Canaz H: Shunt revision rates in myelomeningocele patients in the first year of life: $A$ retrospective study of 52 patients. Childs Nerv Syst 34:919923, 2018

3. Anegbe AO, Shokunbi MT, Oyemolade TA, Badejo OA: Intracranial infection in patients with myelomeningocele: Profile and risk factors. Childs Nerv Syst 35(11):2205-2210, 2019

4. Arslan M, Eseoglu M, Gudu BO, Demir I, Kozan A, Gokalp A, Sosuncu E, Kiymaz N: Comparison of simultaneous shunting to delayed shunting in infants with myelomeningocele in terms of shunt infection rate. Turk Neurosurg 21:397-402, 2011

5. Back SA: Congenital malformations of the central nervous system. In: Avery's Diseases of the Newborn. Elsevier Inc., 2005

6. Bennett KA, Carroll MA, Shannon CN, Braun SA, Dabrowiak ME, Crum AK, Paschall RL, Kavanaugh-McHugh AL, Wellons JC, Tulipan NB: Reducing perinatal complications and preterm delivery for patients undergoing in utero closure of fetal myelomeningocele: Further modifications to the multidisciplinary surgical technique. J Neurosurg Pediatr 14(1):108-114, 2014 
7. Blount JP, Durham SR, Klimo Jr P, Assassi N, Bauer DF, Beier $A D$, Flannery AM, McClung-Smith $C$, Nikas DC, Rehring $P$, Tamber MS, Tyagi R, Mazzola CA: Congress of neurological surgeons systematic review and evidence-based guideline on the management of patients with myelomeningocele: Whether persistent ventriculomegaly adversely impacts neurocognitive development. Neurosurgery 85(3):414-416, 2019

8. Caldarelli M, Di Rocco C, La Marca F: Shunt complications in the first postoperative year in children with meningomyelocele. Childs Nerv Syst 12(12):748-754, 1996

9. Canfield MA, Ramadhani TA, Shaw GM, Carmichael SL, Waller DK, Mosley BS, Royle MH, Olney RS, National Birth Defects Prevention Study: Anencephaly and spina bifida among Hispanics: Maternal, sociodemographic, and acculturation factors in the National Birth Defects Prevention Study. Birth Defects Res A Clin Mol Teratol 85(7):637-646, 2009

10. Chadduck WM, Reding DL: Experience with simultaneous ventriculo-peritoneal shunt placement and myelomeningocele repair. J Pediatr Surg 23:913-916, 1988

11. Chapman PH, Swearingen B, Caviness VS: Subtorcular occipital encephaloceles: Anatomical considerations relevant to operative management. J Neurosurg 71:375-381, 1989

12. Corroenne R, Zhu KH, Johnson E, Johnson R, Whitehead WE, Espinoza J, Castillo J, Castillo H, Orman G, Huisman T, Mehollin-Ray AR, Shamshirsaz AA, Nassr AA, Belfort MA, Sanz Cortes M: Impact of the size of the lesion in prenatal neural tube defect repair on imaging, neurosurgical and motor outcomes: A retrospective cohort study. BJOG 128(2):392399, 2021

13. Di Rocco C, Marchese E, Velardi F: A survey of the first complication of newly implanted CSF shunt devices for the treatment of nontumoral hydrocephalus. Childs Nerv Syst 10(5): 321-327, 1994

14. Eseoglu M, Eroglu A, Kemer S, Arslan M: Determination of the effect of diameter of the sac on prognosis in 64 cases operated for meningomyelocele. Korean J Spine 14(1):7, 2017

15. Faraj $M$, Ashrafzadeh $F$, Ariamanesh A, Faraji S: Surgical outcome of patients with meningomyelocele treated with a team approach. Neurosurgery Quarterly 16(2):85-88, 2006

16. Farmer DL, von Koch CS, Peacock WJ, Danielpour M, Gupta $\mathrm{N}$, Lee $\mathrm{H}$, Harrison MR: In utero repair of myelomeningocele: Experimental pathophysiology, initial clinical experience, and outcomes. Arch Surg 138(8):872-878, 2003

17. Gamache Jr FW: Treatment of hydrocephalus in patients with meningomyelocele or encephalocele: A recent series. Childs Nerv Syst 11(8):487-488, 1995

18. Greene WB, Terry RC, DeMasi RA, Herrington RT: Effect of race and gender on neurological level in myelomeningocele. Dev Med Child Neurol 33(2):110-117, 1991

19. Gross RH, Cox A, Tatyrek R, Pollay M, Barnes WA: Early management and decision making for the treatment of myelomeningocele. Pediatrics 72:450-458, 1983

20. Hubballah MY, Hoffman HJ: Early repair of myelomeningocele and simultaneous insertion of ventriculoperitonal shunt: Technique and results. Neurosurgery 20(1):21-23, 1987

21. Idowu OE, Apemiye RA: Outcome of myelomeningocoele repair in sub-Saharan Africa: The Nigerian experience. Acta Neurochir (Wien) 150(9):911-913, 2008
22. Iskandar BJ, McLaughlin C, Oakes WJ: Split cord malformations in myelomeningocele patients. $\mathrm{Br} \mathrm{J}$ Neurosurg 14(3):200-203, 2000

23. Jabaiti S, Al-Zaben KR, Saleh Q, Abou Alrob M, Al-Shudifat AR: Fasciocutaneous flap reconstruction after repair of meningomyelocele: Technique and outcome. Pediatr Neurosurg 50:344-349, 2015

24. Kim YG, Jung HW, Kim HJ, Cho BK, Han DH, Choi KS, Sim BS: Clinical study on myelomeningocele. J Korean Neurosurg Soc 15(1):133-140, 1986

25. Kshettry VR, Kelly ML, Rosenbaum BP, Seicean A, Hwang L, Weil RJ: Myelomeningocele: Surgical trends and predictors of outcome in the United States, 1988-2010. J Neurosurg Pediatr 13(6):666-678, 2014

26. Liptak GS, Masiulis BS, McDonald JV: Ventricular shunt survival in children with neural tube defects. Acta Neurochirurgica 74: 113-117, 1985

27. Lorber J: Results of treatment of myelomeningocele: An analysis of 524 unselected cases, with special reference to possible selection for treatment. Dev Med Child Neurol 13(3): 279-303, 1971

28. Machado HR, de Oliveira RS: Simultaneous repair of myelomeningocele and shunt insertion. Childs Nerv Syst 20(2):107-109, 2004

29. Mattogno PP, Massimi L, Tamburrini G, Frassanito P, Di Rocco C, Caldarelli M: Myelomeningocele repair: Surgical management based on a 30-year experience. Acta Neurochir Suppl 124:143-148, 2017

30. McCarthy DJ, Sheinberg DL, Luther E, McCrea HJ: Myelomeningocele-associated hydrocephalus: Nationwide analysis and systematic review. Neurosurg Focus 47(4):E5, 2019

31. McLone DG, Naidich TP: Myelomeningocele: Outcome and late complications. In: McLaurin RL, Schut L, Venes JL, Epstein F (eds), Pediatric Neurosurgery. Philadelphia: Saunders, 1989: 53-70

32. Mealey Jr J, Dzenitis AJ, Hockey AA: The prognosis of encephaloceles. J Neurosurg 32(2):209-218, 1970

33. Mirzai H, Ersahin Y, Mutluer S, Kayahan A: Outcome of patients with meningomyelocele: The Ege University experience. Childs Nerv Syst 14(3):120-123, 1998

34. Mohamed Moussa WM, Aly Mohamed MA: Efficacy of postoperative antibiotic injection in and around ventriculoperitoneal shunt in reduction of shunt infection: A randomized controlled trial. Clin Neurol Neurosurg 143:144149, 2016

35. Moron AF, Barbosa MM, Milani H, Sarmento SG, Santana E, Suriano IC, Dastoli PA, Cavalheiro S: Perinatal outcomes after open fetal surgery for myelomeningocele repair: A retrospective cohort study. BJOG 125(10):1280-1286, 2018

36. Musluman AM, Karsidag S, Sucu DO, Akcal A, Yilmaz A, Sirinoglu D, Aydin Y: Clinical outcomes of myelomeningocele defect closure over 10 years. J Clin Neurosci 19(7):984-990, 2012

37. Onrat S, Seyman H, Konuk M: Incidence of neural tube defects in Afyonkarahisar, Western Turkey. Genet Mol Res 8: 154-161, 2009 
38. Rodrigues ABD, Krebs VLJ, Matushita H, de Carvalho WB: Short-term prognostic factors in myelomeningocele patients. Childs Nerv Syst 32(4):675-680, 2016

39. Salem-Memou S, Chavey S, Elmoustapha H, Mamoune A, Moctar A, Salihy S, Boukhrissi N: Hydrocephalus in newborns and infants at the Nouakchott National Hospital. Pan Afr Med J 36:184, 2020

40. Shokunbi T, Adeloye A, Olumide A: Occipital encephalocoeles in 57 Nigerian children: A retrospective analysis. Childs Nerv Syst 6(2):99-102, 1990

41. Tamburrini G, Frassanito P, lakovaki K, Pignotti F, Rendeli C, Murolo D, Di Rocco C: Myelomeningocele: The management of the associated hydrocephalus. Childs Nerv Syst 29:15691579,2013
42. Texakalidis P, Tora MS, Wetzel JS, Chern JJ: Endoscopic third ventriculostomy versus shunt for pediatric hydrocephalus: A systematic literature review and meta-analysis. Childs Nerv Syst 35(8):1283-1293, 2019

43. Ulsenheimer MM, Antoniuk SA, dos Santos LH, Ceccatto MP, Silveira AE da, Ruiz AP, Egger P, Bruck I: Myelomeningocele: A Brazilian university hospital experience. Arq Neuropsiquiatr 62(4):963-968, 2004

44. Zhao R, Shi W, Yang H, Li H: Endoscopic third ventriculostomy instead of shunt revision in children younger than 3 years of age. World Neurosurg 88:92-96, 2016 